\title{
AS LUTAS DE CLASSES NO CAMPO DA MEMÓRIA
}

\author{
LAS LUCHAS DE CLASES EN EL CAMPO DE LA MEMORIA
}

CLASS STRUGGLES IN THE FIELD OF MEMORY

DOI: $10.22481 /$ rbba.v10i01.8806

Alexandre de Jesus Santos

Secretaria de Educação do Estado da Bahia, Bahia, Brasil

ID Lattes: http://lattes.cnpq.br/0045957458422096

ORCID: https://orcid.org/0000-0001-6041-8036

Endereço eletrônico: alexandre_magno2@ @otmail

\begin{abstract}
RESUMO
O presente artigo possui por objetivo evidenciar a importância das lutas entre as classes sociais no âmbito do complexo social da memória, buscando explorar suas consequências para o campo da consciência e das lutas de classes no tempo presente. Procura-se demonstrar, sobretudo, que a forma como o ser social lembra e se apropria do passado é decisivo para a materialização do seu comportamento social ético no mundo. Segundo essa perspectiva, a forma como os acontecimentos passados são lembrados deve ser uma preocupação constante das classes sociais no tempo presente. Por essa razão, a luta de classes no campo da memória, a disputa processada pelas classes sociais acerca da forma e do conteúdo a ser lembrado, se torna, a cada dia, mais substancial, visto que a afirmação ou a negação deste sistema de relações sociais perpassa, também, pela forma como se lembra e se entende tais relações.
\end{abstract}


Palavras-chave: Lutas de classes; Complexo social da memória; Ideologia; Consciência de classe.

\title{
RESUMEN
}

El presente artículo pretende destacar la importancia de las luchas entre clases sociales dentro del complejo social de la memoria, buscando explorar sus consecuencias para el campo de la conciencia y las luchas de clase en la actualidad. Pretende demostrar, sobre todo, que la forma en que el ser social recuerda y se apropia del pasado es decisiva para la materialización de su comportamiento social ético en el mundo. Según esta perspectiva, la forma en que se recuerdan los acontecimientos del pasado debería ser una preocupación constante de las clases sociales en el presente. Por ello, la lucha de clases en el campo de la memoria, la disputa procesada por las clases sociales sobre la forma y el contenido a recordar, se vuelve, cada día, más sustancial, ya que la afirmación o negación de este sistema de relaciones sociales pasa también por la forma en que estas relaciones son recordadas y comprendidas.

Palabras clave: Luchas de classes; Complejo social de la memoria; Ideología; Conciencia de classe.

\begin{abstract}
The present article aims to evidence the importance of the struggles between social classes within the social complex of memory, seeking to explore its consequences for the field of consciousness and class struggles in the present time. It seeks to demonstrate, above all, that the way social beings remember and appropriate the past is decisive for the materialization of their ethical social behavior in the world. According to this perspective, the way past events are remembered should be a constant concern of social classes in the present time. For this reason, the class struggle in the field of memory, the dispute processed by social classes about the form and content to be remembered, becomes, every day, more substantial, since the affirmation or denial of this system of social relations also passes through the way these relations are remembered and understood.
\end{abstract}

Keywords: Class struggles; Social complex of memory; Ideology; Class consciousness 
Devemos entender o "passado" em sentido ontológico e não no sentido da teoria do conhecimento. Considerado do ponto de vista da teoria do conhecimento, o passado é o que já é inteiramente transcorrido. Ontologicamente, ao contrário, o passado nem sempre é algo passado, mas exerce uma função no presente; e não todo o passado, mas uma parte dele que, aliás, varia (LUKÁCS, 2014, p. 43).

\section{INTRODUÇÃO}

Conforme afirma Luxemburgo (2017), a construção de uma sociedade emancipada não pode ser estabelecida por via de decreto. Se a crítica da Espartaquista foi inicialmente dirigida para os acontecimentos relativos à Revolução Russa de 1917, a lição permanece absolutamente atual, pois a sociedade capitalista não será superada a menos que a classe trabalhadora possa se organizar politicamente enquanto uma classe-para-si. Para este propósito, contudo, a memória - sempre mediada pela ideologia - pode constituir tanto um óbice, na medida em que se articula com as demandas de naturalização e validade do sistema social vigente, como também em um impulso positivo para se atingir a consciência de classe necessária (MÉSZÁROS, 2008) para o engendramento de uma sociedade emancipada. Conforme aduz Mészáros (2004), o posicionamento dos indivíduos de classe - ou seja, a escolha - diante das ideologias constituídas é que vai determinar os rumos da história. Do mesmo modo, mutatis mutandis, é a luta de classes no campo da memória que também poderá contribuir substantivamente para o desenvolvimento de uma consciência de classe que possa implicar numa ética voltada, fundamentalmente, para a práxis, conforme propõe Heller (2014).

Nesta perspectiva, este artigo possui por objetivo trazer à baila toda a relevância do debate em torno da memória enfocando, principalmente, a relação desta com as lutas de classes e, desta última, com o campo da memória, compreendido enquanto complexo social que, no atual estágio de desenvolvimento das forças produtivas e da organização social vigente, está entremeado pelas lutas entre as classes sociais; do mesmo modo, busca-se refletir acerca da situação em que se encontra esta entrincheirada luta no campo da memória. Assim, esse debate em torno da memória é, também, e necessariamente, um debate sobre a luta e a consciência de classes, de modo que possui relevância particular para ambos os aspectos. Pretende-se com isso afirmar peremptoriamente que o caráter de classe é indissociável de todas as lutas que podem ser travadas (e, frequentemente, são) no âmbito do complexo social da memória, pois a luta pela memória que poderia ser chamada, sem grandes entraves, de autêntica, é também a luta pela construção da identidade de classe, pelo autorreconhecimento de si, pelo desenvolvimento 


\section{AS LUTAS DE CLASSES NO CAMPO DA MEMÓRIA}

da consciência de classe e, por fim, pelo posicionamento ético radical na intrincada luta pelo controle do metabolismo social. As lutas que podem e são travadas cotidianamente no campo da memória são, ao mesmo tempo, a manifestação dos interesses divergentes, contraditórios e irreconciliáveis das classes sociais.

Aqui, é importante atentar-se para dois aspectos: o primeiro refere-se ao fato de que sendo a memória uma categoria imprescindível para o devir humano e para a criação do mundo humano-social, ela desempenha neste processo diversos papéis, não apenas na esfera do trabalho a partir da criação do novo e da recriação do mesmo, mas também no âmbito do ethos, da tradição, dos valores morais e éticos, etc., sendo imperativa também para a reprodução social tanto do indivíduo quanto do gênero humano e; o segundo diz respeito ao ineliminável caráter ideológico adquirido pela memória nas sociedades marcadas por contradições entre as classes sociais, que não somente posiciona o sujeito em um dos campos antagônicos relativos à luta pelo controle sociometabólico da sociedade, como também exerce um papel fundamental para a reflexão acerca da luta e da consciência de classes de tal maneira que, compreender as memórias como contradições emanadas das relações materiais ou como memórias harmônicas resultantes dos processos de assimilação ideológicas das ideologias dominantes, possui uma relação simbiótica com os interesses inconciliáveis das classes antagônicas.

\section{MEMÓRIA, SOCIEDADE, LEMBRANÇA E ESQUECIMENTO}

Assim como a ideologia que se espraia para todos os complexos sociais de modo que tudo, nas sociedades de classes, está impregnado de ideologia, as lutas de classes, a mais fundamental em torno do controle do metabolismo social atinge não somente o complexo econômico, mas se manifesta também no campo da memória. Este, por sua vez, é um campo de disputa que desempenha um papel crucial na luta de classes, pois, é neste complexo social que será disputada a forma como os conteúdos de memória serão lembrados pelos sujeitos.

Todas as memórias são, necessariamente, memórias de classe. A razão de tal afirmação encontra-se no fato de que o sujeito não pode se autonomizar completamente em relação às determinações estruturais da sociedade na qual se reproduz, dado que os sujeitos são, indubitavelmente, desdobramentos necessários do conjunto das relações sociais. Neste sentido, todos os seus atos produzem memórias que não podem ser dissociadas da sua condição material. 


\section{AS LUTAS DE CLASSES NO CAMPO DA MEMÓRIA}

Desse modo, ainda que essa possibilidade exista, de forma geral, não se pode obliterar no sujeito a memória do ato em si. Em outras palavras, refletindo sobre o conhecimento que se pode adquirir acerca do processo de escravidão negra no Brasil, ou mesmo de um ato particular realizado pelo sujeito no dia em que ele foi assistir a uma partida de futebol, seja no campo de terra da comunidade, ou em um estádio oficial de um clube determinado lotado de torcedores, essas memórias em si, ainda que ontologicamente distintas - pois uma foi adquirida pela mediação de um estudo particular e outra foi efetivamente vivida pelo sujeito - , não podem, em hipótese alguma, em condições normais, serem apagadas.

Cabe aqui um breve, mas, necessário parêntese para estabelecer uma distinção entre memória e história. A história, no sentido amplo e ontológico, como afirmou Marx e Engels (2007) nos idos de 1845-46 nada mais é que a atuação do homem no mundo para produzir a sua vida material; ao fazer isso, esses homens, se relacionando com a natureza e uns com os outros, fazem suas próprias histórias. Contudo, ao construir suas histórias singulares constroem, ao mesmo tempo, a história humana enquanto totalidade social. Assim, para os propósitos deste artigo é preciso apenas estabelecer a seguinte distinção: ao produzir a sua história os homens produzem, ao mesmo tempo e inevitavelmente, a memória dos acontecimentos, dos atos singulares desdobrados na vida cotidiana, das relações sociais, etc., sendo que isso independe da percepção do sujeito. Essa é, de algum modo, uma memória vivida que não precisa, necessariamente, ter sido vivida pelo sujeito que a reproduz, mas pode ter chegado a ele por intermédio da tradição passada pelas gerações anteriores.

Todavia, quando se chega em um momento da história em que a forma de se conhecer o mundo é sistematicamente substituída pela técnica e a educação formal, na qual a tradição oral perde força, conforme proposição de Lukács (2013), essa memória vivida perde força e os conhecimentos dos acontecimentos históricos passam a ser adquiridos pelos sujeitos de uma outra forma, ou seja, pela mediação da história no sentido estrito, de um estudo sistemático e fechado sobre um determinado acontecimento.

Certamente, ninguém na sociedade contemporânea pode afirmar que possui, efetivamente, uma memória acerca da Revolução Francesa de 1789 ou mesmo da vida social daquele período histórico. Seguramente, considerando Matusalém apenas uma miragem, ninguém vive tanto tempo e, portanto, não possui uma memória vivida deste período. Quando, deste modo, o sujeito contemporâneo lembra da referida revolução ele lembra, na verdade, do conhecimento adquirido de uma forma já sistematizada pelo conhecimento histórico acerca dos 


\section{AS LUTAS DE CLASSES NO CAMPO DA MEMÓRIA}

acontecimentos daquela revolução específica. Afinal, não se pode lembrar do que efetivamente não foi vivido pelo sujeito ou a geração - exceto, talvez, considerando o endrômino engodo da terapia de vidas pregressas. Neste sentido, ainda que ao falar sobre um dado acontecimento relativo à Revolução Francesa como a queda da Bastilha, por exemplo, ainda que a imagem evocada na memória seja a da própria Bastilha e não do livro de Hobsbawm (1977) no qual versa sobre tal acontecimento, sobre o filme que representa essa realidade - mesmo mediado por outra linguagem e permeado pela licença poética - ou sobre o livro didático que se possa ter lido com esse conteúdo, o que se lembra efetivamente é do conhecimento adquirido acerca desta revolução e não da revolução em si.

É preciso salientar, nessa perspectiva, que a lembrança de um acontecimento vivido ou de um conhecimento adquirido guarda uma relação intrínseca com a memória, pois ambas estão nela contidas. Entretanto, o reflexo da realidade adquirido pela mediação de uma instrução normativa, já sistematizada e interpretada por uma perspectiva específica [epistemológica, ideológica, historiográfica, etc.], e o reflexo resultante de um processo de vida real, ou seja, realmente vivido pelo sujeito no âmbito das suas experiências e da sua vida cotidiana possuem, sem sombra de dúvidas, níveis ontológicos bastante distintos. Em ambos os casos, contudo, há uma disputa pela memória, seja pelos acontecimentos recentes vividos, seja pelas lembranças dos conhecimentos dos acontecimentos antigos.

A memória, neste sentido, está relacionada aos acontecimentos passados realmente vividos pelo sujeito ou transmitido pelas gerações pretéritas, estando, por outro lado, totalmente articulada às necessidades e aos imperativos materiais do tempo presente; ao passo que a história é, no sentido mais amplo possível, a produção da vida material e, no sentido estrito, enquanto disciplina científica, o estudo sistemático de tais acontecimentos, do macro ou do microcosmos, protagonizados pelos homens e transmitidos para os sujeitos na forma de conhecimento sistematizados.

Dito isso, é preciso inferir que um momento vivido pelo sujeito que possa ter um significado individual, ou mesmo coletivo não pode, a rigor, ser obliterado da memória do sujeito senão em detrimento das determinações sociais que podem impor o esquecimento ou a lembrança de tais memórias. Todavia, o esquecimento habitualmente pode ocorrer quando essas lembranças perdem o seu sentido, seja para a sociedade, seja para o sujeito, tal como Halbwachs (1990) já havia apontado ao discutir a problemática da memória coletiva. Muito embora, tanto o sujeito pode lembrar de coisas que socialmente já perderam o significado, pela relação 


\section{AS LUTAS DE CLASSES NO CAMPO DA MEMÓRIA}

particular que ele tem com esses acontecimentos passados, quanto pode querer particularmente esquecer, mas ser socialmente obrigado a lembrar pela relevância social que uma determinada memória ainda pode ter. Não é supérfluo lembrar que, neste caso particular, o conceito de lugares de memória de Nora (1993) pode gozar de alguma relevância.

Condições atípicas, no entanto, podem levar a obliteração da memória. O esquecimento de uma memória traumática, por exemplo, no campo das psicopatologias, pode ser necessário para o processamento de uma cura. No mesmo sentido, traumas e lesões físicas no cérebro, sobretudo na neurofisiologia responsável pela memória, ou mesmo enfermidades como a doença de Alzheimer, podem provocar o esquecimento forçado por parte do sujeito. Entrementes, essas são condições anômalas no processo de esquecimento. A rigor, o esquecimento é, antes, uma determinação principalmente social.

Não somente o esquecimento, mas também a lembrança, seu par dialético, devem ser entendidas como determinações, em regra, especialmente sociais. Lembrar de determinados acontecimentos, exatamente como sugeriu Lukács (2014), pensando a lembrança e o esquecimento no sentido ontológico, deve ser relacionado à necessidade social de um tempo ou uma conjuntura histórica específica e não como um ato singular "puro" realizado pela subjetividade "pura" do sujeito social. Por esta perspectiva, lembrar dos horrores produzidos durante a escravidão negra no Brasil, ou do holocausto produzido pelo nazifascismo durante a Segunda Guerra Mundial, ou ainda das perseguições étnicas protagonizadas pela "supremacia branca", pode ter um sentido ético e um significado social sobre aquilo que não deve ser esquecido, deve ser combatido e, assim, não deve ser repetido. A lembrança e o esquecimento de determinados atos particulares ou mesmo coletivos devem ser entendidos primeiro, como determinações históricas daquilo que se valoriza socialmente em relação àquilo que se deve lembrar, e; segundo, relacionado à percepção particularizada do indivíduo acerca de um determinado ato e como isso o afeta.

\section{MEMÓRIA E LUTAS DE CLASSES}

Volta-se, aqui, para as primeiras afirmações deste tópico: se é verdade que a memória dos atos, sua lembrança e esquecimento, ou seus conteúdos de memória não podem ser obliterados sem que haja determinações principalmente sociais para que tal coisa possa ocorrer, não se pode fazer a mesma afirmativa no que concerne à problemática das formas, pois ela é 


\section{AS LUTAS DE CLASSES NO CAMPO DA MEMÓRIA}

frequentemente alterada de acordo com os conflitos sociais e as lutas de classes no campo da memória. É verdade que também o conteúdo lembrado é determinado historicamente, mas o conteúdo em si não é passível [facilmente] de mudança, sobretudo quando ele é derivado de experiências empíricas realizadas pelo sujeito. A forma, contudo, como se lembra ou deixa-se de lembrar dele é frequentemente alterada em detrimento dos conflitos sociais e das lutas de classes que se processam no seio da história. Forma e conteúdo, também aqui, não perdem a sua unidade dialética, muito embora, é preciso reconhecer, que a mudança na forma como se lembra é significativamente mais volátil do que o conteúdo a ser lembrado.

Não se quer dizer com isso que, no campo da memória, não haja uma relação dialética entre forma e conteúdo, aparência e essência, dos conteúdos de memória, porém, embora tratese de uma determinação reflexiva, a forma, muito mais volátil, a partir da qual as lembranças são evocadas está muito mais relacionada às determinações sociorreprodutivas que se desenrolam na sociedade vigente do que, especificamente, a uma alteração do conteúdo da lembrança, mesmo que essa possa ser resultante dessas mesmas determinações. É preciso desenvolver melhor essa formulação para que não reste muito espaço para dúvidas.

Analisando a informação contida na memória acerca de uma partida de futebol a qual o espectador não apenas obteve algum conhecimento teórico, mas participou efetivamente da sua consecução constitui um ato que, salvo as possibilidades apresentadas, ela não pode ser obliterada. A memória da partida, enquanto houver significado social e, também, para o sujeito, pensando na relação reflexiva entre o indivíduo e a sociedade, vai permanecer preservada na sua memória até que, em algum momento e por alguma razão, caia no esquecimento. Contudo, se a partida de futebol em questão possui um significado social [comunitário] mais amplo, a ponto de referir-se a uma parcela significativa da sociedade ou mesmo a um grupo social específico, como, por exemplo, os torcedores de um determinado time, a forma como o sujeito vai compreender essa partida ao lembrar-se dela estará condicionada por uma série de determinações sociais nas quais, também esse sujeito que lembra, desempenha um papel importante, na medida em que gozando de uma formação social, independentemente de qual for, pode reafirmar, negar, reinterpretar, se omitir, etc. em relação à forma como a memória está sendo evocada.

Desta maneira, se a partida de futebol em questão for a semifinal da Copa do Mundo do Brasil ocorrida no ano de 2014 na qual o jogo foi perdido pelo placar de 7x1 para a seleção da Alemanha, esse sujeito poderá se lembrar desse fato das mais diversas formas possíveis. 


\section{AS LUTAS DE CLASSES NO CAMPO DA MEMÓRIA}

Desde a forma vergonhosa como a Seleção Brasileira foi goleada pela Seleção Alemã trazendo vexame para o Brasil no mundo futebolístico, ou ainda a maneira aguerrida como a Seleção Brasileira, diante de toda a superioridade da Seleção Alemã foi suficientemente combativa para perder a partida apenas por seis gols de diferença. Esse mesmo sujeito pode ter, ainda, uma visão beligerante contraposta a essas duas apresentadas, relacionada à forma como o dinheiro público foi utilizado para financiar esquemas milionários de venda de entretenimento e locus de corrupção em detrimento da supressão das necessidades mais básicas e fundamentais da população brasileira e mundial. Como esse sujeito particular vai se lembrar da Copa do Mundo de 2014? Evidentemente, uma forma de lembrança não é, no caso do exemplo supramencionado, necessariamente excludente em relação a outra, de modo que um mesmo sujeito pode ostentar a visão de como esse momento foi vexatório, ao mesmo tempo em que foi amplamente utilizado para o enriquecimento ilícito, o superfaturamento, o financiamento irregular de campanhas eleitorais como posteriormente ficou evidenciado nas investigações conduzidas pela Polícia Federal.

Antes de entrar no mérito relativo às determinações da lembrança, é preciso esclarecer que alguns acontecimentos sociais são tão significativos que aquele sujeito que não guarda nenhuma relação afetiva em relação a ele acaba por ser afetado, dado a forma como esse acontecimento envolve a totalidade social. Nesse sentido, mesmo o sujeito, pensando no brasileiro, que não gosta nem se afeta pelo futebol, dado a dimensão mundial deste evento e o fato de ter ocorrido no Brasil, a maneira como afetou a economia, a política, a segurança pública, a ocupação do espaço urbano, a especulação imobiliária, etc., vai certamente se lembrar dos fatídicos acontecimentos de 2014 e alguns dos seus desdobramentos. Essa lembrança em particular sai, portanto, do âmbito do controle do sujeito acerca daquilo que ele lembra ou esquece, mas dada a sua dimensão social esse sujeito é - poderia se dizer - , "obrigado a lembrar".

Agora, tomando como exemplo um acontecimento relativamente recente e muito mais significativo do ponto de vista das lutas de classes, pode-se aludir como objeto a ser disputado pelas classes sociais a memória acerca da Ditadura Civil-Militar de 1964 no Brasil. Tal acontecimento recente, recebe incursões não apenas da memória transmitida às gerações posteriores por aqueles que efetivamente viveram esse fatídico momento da história em perspectivas contrapostas, como opressores ou oprimidos, como também por parte da historiografia que se debruça sobre ele. 


\section{AS LUTAS DE CLASSES NO CAMPO DA MEMÓRIA}

A memória dos militares sobre esses acontecimentos, repassadas para o âmbito circunscrito do círculo de relações sociais que estabelece, certamente entende esse momento como necessário para salvaguardar os interesses patrióticos da nação em 'detrimento do perigo eminente do avanço das formas e conquistas do comunismo mundo afora'; Pouco importa aqui, efetivamente, se esse opressor era 'meramente' um soldado assalariado que, nessa condição, se vincula materialmente muito mais à classe dos trabalhadores do que da burguesia; o que implica efetivamente é que esse sujeito se vincula, ideologicamente, a interpretação e a justificação dos acontecimentos alinhados à ideologia burguesa, por mais estapafúrdia que possa ser essa justificativa em relação ao movimento real do objeto em questão [a ditadura]; a memória transmitida por esse sujeito para os seus filhos e netos, círculos de amigos e familiares será, muito provavelmente atrelada a esse interesse material de classe que justifica tal acontecimento.

Isso não implica dizer, necessariamente, que esses sujeitos para os quais tais memórias serão transmitidas, ao longo do decurso do desenvolvimento de sua vida não possam confrontar as versões contrapostas apresentadas sobre o mesmo acontecimento e chegar a uma conclusão diferente, assumindo uma outra perspectiva sobre o evento, reafirmando ou reelaborando a interpretação. Objetivamente, essa possibilidade que se materializa cotidianamente em cada uma das decisões alternativas (LUKÁCS, 2013) tomadas pelo sujeito é a margem de atuação que permite a tomada de consciência ou a ampliação dos processos de alienação do sujeito em sua reprodução no mundo.

No sentido contrário, aqueles sujeitos que sobreviveram à repressão política, à censura, à tortura, que não foram assassinados nesse período, aqueles que efetivamente sofreram com a implantação do famigerado regime, possuem sobre ele uma memória vivida totalmente contraposta a dos militares. Esses oprimidos, por sua vez, produzem e reproduzem para as gerações relacionadas ao seu ciclo de relações sociais, memórias totalmente contrapostas à memória dos opressores, entendendo esse momento como um capítulo absolutamente tenebroso da história do Brasil o qual não deverá, jamais, sob nenhuma circunstância ou justificativa, se repetir. É desnecessário repetir aqui que as mesmas possibilidades alternativas que subjazem o sujeito vinculado ideologicamente à classe opressora, aos interesses da burguesia são igualmente válidos para aqueles afetados pela ideologia da classe trabalhadora. A diferença, obviamente, consiste no nível de proximidade e apreensão daquilo que a realidade foi em si mesma, uma vez que essa é distorcida pela classe opressora - não necessariamente de forma deliberada - ao passo que a classe trabalhadora tem apenas o interesse em revelar sua verdade. 


\section{AS LUTAS DE CLASSES NO CAMPO DA MEMÓRIA}

No mesmo sentido, a disputa em torno da produção do conhecimento está entremeada pelas lutas entre as classes sociais, sendo que é esse conhecimento produzido que vai, do ponto de vista de uma educação formal, tornar-se o cabedal de informações acerca dessa referida ditadura para as gerações que não vivenciaram efetivamente esse processo e, portanto, não tem uma memória vivida sobre o que foi a Ditadura Civil-Militar brasileira. Por qual perspectiva os livros didáticos, que formam milhares de pessoas que não viveram esse momento particular da história do Brasil, vão apresentar esse fatídico acontecimento e todas as suas respectivas implicações, como revolução ou golpe, como a "Ditabranda Militar"?

Assim, como foi afirmado, tratar esse momento como golpe ou revolução possui relação intrínseca com os interesses materiais das classes que se antagonizam e disputam a memória e a ideologia na sociedade contemporânea. Atualmente, no cenário político institucional subjacente, a luta em torno da memória sobre a Ditadura Militar ganha novos contornos, pois os mandatários do poder político passam a apresentar oficialmente esse período da história do Brasil como a verdadeira panaceia - sugerindo, inclusive, mudanças no conteúdo dos livros didáticos que, até então, caracterizam esse período da história do Brasil como uma ditadurai ${ }^{\mathrm{i}}$.

Deste modo, a memória da ditadura é, seguramente, uma memória recente que ainda está em disputa, em aberto, não somente a sua lembrança e/ou seu esquecimento têm um significado puramente social, mas também e, sobretudo, a forma como esses acontecimentos são lembrados está estritamente relacionado à luta entre as classes sociais no campo da memória com implicações graves para o âmbito da consciência de classe - como será evidenciado no último tópico deste capítulo.

Neste sentido, é preciso dizer que as formulações de Halbwachs (2004; 1990), ao restringir à memória coletiva à problemática dos grupos sociais, mas, ao mesmo tempo dissociando-a de grupos muito mais amplos e mais estruturados, realiza uma interpretação que, ao negar as lutas de classes como força motriz das disputas em torno da memória e sua própria matriz estrutural, vai no sentido de se adequar aos imperativos ideológicos burgueses que, conforme argumentou Mészáros (2004), busca a naturalização da forma de ser da sociedade contemporânea. Neste sentido preciso, Halbwachs considera a memória coletiva como sendo aquela pertencente a um determinado grupo que se insere dentro de um dado contexto social, travado pelas estruturas dos grupos aos quais participa, mas ela é antes e, sobretudo, pertencente à classe inserida numa estrutura sociorreprodutiva muito mais ampla e ineliminável enquanto existir esta sociedade. 


\section{AS LUTAS DE CLASSES NO CAMPO DA MEMÓRIA}

As formulações de Halbwachs influenciaram profundamente a construção das chamadas memórias nacionais conforme propõe Ortiz, (2012); Vale lembrar que parte significativa da historiografia francesa passou quase o século XX inteiro preocupado com a construção de uma memória nacional, seja evocando a tradição francesa há muito destruída pelos imperativos sociorreprodutivos do capital, ou mesmo fazendo uma crítica ferrenha a ela. Basta fazer referência aqui às sucessivas gerações da Escola dos Annales e a fundação da "história das mentalidades" e da "nova história".

Importa salientar sobre esse processo que, se a memória em torno da ditadura está em disputa ganhando novos capítulos a cada momento, alguns aspectos da história geral do Brasil já estão, em certo sentido, estigmatizados, ainda que, mesmo estes também frequentemente entram em disputa. A título de exemplo pode-se citar o papel atribuído à Isabel, a princesa, no processo de abolição da escravatura, que ao colocá-la como protagonista deste acontecimento, esconde, ao mesmo tempo, todo o processo de luta protagonizado pelos negros escravizados para alcançar a sua liberdade, bem como todas as outras forças externas e internas que de muitas maneiras foram decisivas para tal realização ${ }^{i i}$. Certamente, a revisitação crítica da historiografia sobre tais acontecimentos têm oferecido contribuições substanciosas no sentido de proporcionar uma reinterpretação desses fatos e, portanto, um novo capítulo na luta pela memória; no mesmo sentido, a tentativa de criar uma identidade nacional forjada a partir da generalização de perspectivas particulares, algo típico da ideologia da classe dominante, que pudesse forjar uma ideia de "povo brasileiro" e, ao mesmo tempo, uma certa unidade, também se enquadra no âmbito dessas lutas.

Ainda segundo Ortiz, a ideologia do sincretismo - fundamentada na sociologia de Gilberto Freyre que considerou o "Brasil [como uma] pluralidade de culturas, diversidade de regiões" (2012, p. 93 [grifo nosso]) ideia resgatada pelo regime militar no seu último decênio pelo Conselho Federal de Cultura - foi calcada na antropologia culturalista, que exprime o contato entre os povos como uma aculturação harmônica dos universos simbólicos sem levar em consideração a situação concreta em que acontece os contatos culturais. Nesse sentido, a antropologia culturalista norte americana dissocia cultura de sociedade, o que permite relacionar os aspectos culturais sem levar em conta os aspectos sociais. A aculturação, desta forma, pressupõe a não manifestação das relações de poder, das contradições estruturais, das lutas entre os estratos e, mesmo, das classes sociais e sua composição, de forma que esta ausência é compreendida como um princípio de democracia. Conforme afirma Ortiz (2012), a 


\section{AS LUTAS DE CLASSES NO CAMPO DA MEMÓRIA}

ideia de cultura para cada um, que se diferencia de uma cultura para todos - crítica ao socialismo - é a apologética de uma cultura democrática que passa a constituir a essência da brasilidade.

Importa salientar, no entanto, que o recontar da história, negligenciando ou minimizando aspectos constituintes da realidade, além de ser uma narrativa ideológica, pois não exprime a complexidade das relações sociais e nem leva em conta os conflitos inerentes à sociedade, ou seja, não propõe o alcance sucessivo da coisa-em-si, é também a construção de uma narrativa histórica que, no caso do Brasil, permeia a sociedade fazendo com que, ao ser assimilada e reproduzida pelo sujeito, quando evocada, esse passa a compreender a realidade a partir desse prisma. A memória, a lembrança do conhecimento acerca desse momento da história do Brasil guarda uma relação direta com a classe dominante que procura, sempre, negar, minimizar os conflitos sociais subjacentes. Deste modo, a forma como o sujeito vai lembrar da escravidão negra no Brasil, a partir da perspectiva apresentada por Gilberto Freyre, como uma verdadeira democracia racial, ou na forma apresentada por Caio Prado Jr. fará toda a diferença não apenas para a compreensão do passado, mas para o entendimento e o posicionamento ético no presente.

Neste sentido, é preciso pensar, que a interpretação por parte do sujeito de um dado acontecimento histórico por uma ou outra perspectiva é, ao mesmo tempo, não apenas uma memória de um conhecimento que contém um viés ideológico, mas também a própria reprodução da ideologia dominante. Nunca é demais lembrar que, conforme afirmam Marx e Engels “As ideias da classe dominante são, em cada época, as ideias dominantes, isto é, a classe que é a força material dominante da sociedade é, ao mesmo tempo, sua força espiritual dominante" (MARX \& ENGELS, 2007, p. 47).

Aqui consiste, precisamente, toda a dificuldade de estabelecer uma separação radical entre memória e ideologia, pois, toda memória sensível aos interesses de classe são, necessariamente, e ao mesmo tempo, objeto de disputas ideológicas viscerais que acabam por determinar a forma como os sujeitos sociais se lembrarão delas e, a partir daí, pensando essa relação revestida pela totalidade social, serão decisivas para o molde do comportamento social do ser no mundo e, por conseguinte, para o posicionamento ético que por ele será executado no âmbito da vida cotidiana.

A disputa pela memória é, ao mesmo tempo, uma disputa ideológica entre as classes sociais pela forma como os acontecimentos serão lembrados, mas, sobretudo, pelas consequências que a forma dessas lembranças poderá causar no comportamento social ético dos 


\section{AS LUTAS DE CLASSES NO CAMPO DA MEMÓRIA}

sujeitos no tempo presente. Compreender a sociedade brasileira imersa no racismo estrutural, ou na democracia racial, embora isso não mude a realidade mesma da sociedade brasileira, na esfera das decisões alternativas que o sujeito pode tomar no decurso da sua vida, fará toda a diferença no seu comportamento social.

Por essa perspectiva, tanto a memória vivida, quanto as lembranças dos conhecimentos sobre determinados acontecimentos históricos contidos na memória, em ambos os casos amplamente articulados às lutas entre as classes sociais, acaba por ser uma expressão da ideologia, frequentemente, da dominante que como classe portadora da normatividade social (MÉSZÁROS, 2004), acaba por permear todos os meandros sociais. Todavia, não se pode negligenciar, em hipótese alguma, as formulações e reproduções protagonizadas pela classe trabalhadora que acabam por colocar em xeque a reprodução do sistema social burguês.

Em suma, o que importa salientar é que, as memórias em disputa são àquelas sensíveis, sobretudo as que exercem influência decisiva direta ou indireta sobre o controle do metabolismo social e, por isso, podem influenciar os comportamentos sociais dos sujeitos tornando-os, nas três posições ideológicas propostas por Mészáros (2004), apologéticos do sistema, críticos românticos dele ou radicalmente avessos a ele que, neste último caso, pode implicar na construção de uma proposta emancipadora para a sociedade.

\section{CONCLUSÃO}

Conforme procurou-se evidenciar ao longo deste artigo, memória e classes sociais guardam uma relação intrínseca, sendo plenamente possível e necessário pensar sobre o desdobramento dessa relação no campo das lutas de classes em torno do complexo social da memória. Assim, de tudo o que foi dito depreende-se que:

a) Todas as memórias, compreendidas como desdobramento de uma estrutura social de classes - como no caso aqui analisado -, são, necessariamente, memórias de classes - pouco importa se o sujeito que as reproduz tem consciência do caráter de classe das suas memórias ou não; contudo, se ele vive e se reproduz numa sociedade fortemente demarcada pelo antagonismo social, pela contradição estrutural entre as classes sociais, esse sujeito não pode ser algo diferente do que é o conjunto das relações sociais a partir das quais se reproduz. As memórias se constituem no terreno da materialidade e, por essa razão, trazem consigo a marca indelével das sociedades de classes quando nelas são consubstanciadas; 


\section{AS LUTAS DE CLASSES NO CAMPO DA MEMÓRIA}

b) A luta de classes, apesar de ocorrer fundamentalmente no campo da luta pelo controle do metabolismo social, se espraia para todos os complexos sociais, da estética a ética, inclusive pelo complexo da memória; a luta de classes no campo da memória é, ao mesmo tempo, uma luta pela identidade de classe, pelo reconhecimento de classe e, por conseguinte, pelo alçar-se à condição de classe-para-si; lembrar de todas as lutas travadas historicamente pela conquista dos direitos trabalhistas, das revoluções protagonizadas com unhas e dentes pela classe trabalhadora, de como ela é cotidianamente usurpada material e espiritualmente pela sociedade vigente ou esquecer e reinterpretar tais acontecimentos pela mediação dos imperativos ideológicos burgueses é, sem dúvidas, fundamental para a luta de classes. A classe trabalhadora precisa apropriar-se das suas memórias, sejam das vitórias ou das derrotas.

Desta maneira, as lutas de classes perpassam, também, pelo complexo social da memória. A luta de classes no campo da memória, essa disputa entrincheirada pela forma como os fatos serão lembrados pelos sujeitos históricos, possui seu papel na consecução dos objetivos de longo prazo colocados na ordem do dia da classe trabalhadora.

\section{REFERÊNCIAS}

HALBWACHS, Maurice. A memória coletiva. $2^{\circ}$. Tradução: Beatriz Sidou. São Paulo: Vértice, 1990.

Los marcos sociales de la memoria. Venezuela; Caracas: Antropos Editorial;

Universidad de la Concepcion, 2004.

HELLER, Agnes. O cotidiano e a história. $10^{\circ}$ ed. Tradução: Carlos Nelson Coutinho e Leandro Konder. São Paulo: Paz e Terra, 2014.

HOBSBAWN, Eric J. A era das revoluções. $2^{\circ}$. Tradução: Maria Tereza Lopes Teixeira e Marcos Pencel. Rio de Janeiro: Paz e Terra, 1977.

LUKÁCS, Georgy. Conversando com Lukács : entrevista a Léo Kofler, Wolfgang Abendroth e Hans Heinz Holz. Tradução: Gisieh Vianna. São Paulo: Instituto Lukács, 2014.

. Para uma ontologia do ser social, 2. Tradução: Ivo Tonet, Ronaldo Vielmi Fortes

Nélio Schneider. São Paulo: Boitempo, 2013.

LUXEMBURGO, Rosa. A revolução Russa. São Paulo: Fundação Rosa Luxemburgo, 2017.

MARX, Karl \& ENGELS, Friedrich. A Ideologia Alemã: Crítica da novíssima filosofia alemã em seus representantes Feuerbach, B. Bauer e Stirner, e do socialismo alemão e seus diferentes profetas, 1845 - 1846. Tradução: prefácio e notas de Marcelo Backes Organização. Rio de Janeiro: Civilização Brasileira, 2007.

MÉSZÁROS, István. Filosofia, ideologia e ciência social. Tradução: Ester Veisman. São Paulo: Boitempo, 2008. 
2004.

O Poder da Ideologia. Tradução: Paulo Cezar Castanheira. São Paulo: Boitempo,

NORA, Pierre. Entre a memória e a história: a problemática dos lugares. Tradução: Yara Aun Khoury. São Paulo: Gallimard, 1993.

ORTIZ, Renato. Cultura brasileira e identidade nacional. 5. São Paulo: Brasiliense, 2012.

RICOEUR, Paul. A memória, a história o esquicimento. Tradução: Alian François [et al.]. Campinas - SP: Editora da UNICAMP, 2007.

\section{NOTAS}

\footnotetext{
${ }^{i}$ Evidentemente, é preciso dizer que, no contexto atual (2020/2021), de exacerbação do discurso irracionalista e propagação deliberada de mentiras (assim chamadas Fake News) coloca-se em foco, com uma importância significativa e um objeto a ser estudado, o problema do discurso mentiroso que se auto reivindica verdadeiro. Evidentemente, entra-se no campo da manipulação da memória pela mediação da mentira mais ardil que está muito além e aquém da disputa de narrativas sobre os acontecimentos históricos objetivos que são antagonizados pelas classes sociais. Esse problema não será analisado nesta tese, mas, certamente, a relação entre memória e manipulação constitui um importante campo de debate ainda em aberto, a despeito do esforço de Paul Ricoeur (2007) neste sentido.

ii É o caso, por exemplo, da pressão internacional, sobretudo, daquela advinda da Inglaterra na defesa dos seus interesses capitalistas particulares que tencionou para o fim do tráfico transatlântico, mas também do movimento abolicionista nacional e internacional que pressionou pelo fim da escravidão.
} 